\title{
Serious upper gastrointestinal complications of NSAIDs and COX-2 selective agents
}

\author{
Guy Sisson · Ingvar Bjarnason
}

Received: 3 November 2010/Accepted: 12 April 2011/Published online: 1 May 2011

(C) Springer Basel AG 2011

The use of non-steroidal anti-inflammatory drugs (NSAIDs) is steadily increasing. The main concerns with this class of drugs are the frequency and severity of their gastrointestinal side effects (Hayllar et al. 1992). This is particularly so now that the focus on their adverse cardiovascular effects, especially with the cyclo-oxygenase (COX)-2 selective agents, seems to be waning.

The interest in the gastrointestinal side effects of NSAIDs and COX-2 selective agents comes from (a) basic researchers that are attempting to elucidate the mechanisms of the damage in order to make provisions to minimise the damage (Wallace et al. 2000; Sigthorsson et al. 2002), (b) from clinicians and regulatory authorities that issue guidelines on their use based on the available evidence, (c) and of course the pharmaceutical industry who attempt to produce safer drugs. They are in fact the main source of funding for NSAID-related research, which may have limitations by itself. Thus, the safety data are accumulated anywhere from the bench to the opinions of administrative armchair speculators. What is of paramount importance when forming an opinion on the gastrointestinal safety aspects of anti-inflammatory analgesics is an awareness of the type of study conducted and the limitations that the particular study involves (Hayllar et al. 1992).

What is not in doubt is that conventional NSAIDs cause damage throughout the whole of the gastrointestinal tract (stomach and small bowel and occasionally the large bowel) (Bjarnason et al. 1993). Basic research, almost all of which comes from rodents using NSAID doses far greater than in man (as per $\mathrm{kg}$ weight), shows that the

G. Sisson · I. Bjarnason ( $₫)$

Department of Gastroenterology, King's College Hospital,

Denmark Hill, London SE5 9RS, UK

e-mail: ingvar.bjarnason@kcl.ac.uk damage is initiated by the biochemical actions of the drugs (Somasundaram et al. 1995) which leads to cellular damage that progresses to micro- and macroscopic damage by the interaction between the luminal contents of the organs (acid in the stomach and bile and bacteria in the small bowel) and impaired mucosal defence, microvascular blood flow and oxygenation all playing an important role. The biochemical actions common to all conventional NSAIDs are their topical effects (affecting the brush border and energy production of mitochondria), and their ability to inhibit COX-1 and 2. Damage can occur after any combinations of two of these actions. The precise consequences and mechanisms of these actions have not been fully established, especially the impact of the COX-2 inhibition. What is, however, more concerning is that there are major discrepancies in what is observed in experimental animals and man. For instance, COX-2 knockout mice (or wild type mice fed a COX-2 selective agent) develop an enteropathy, which may lead to perforation and death (Morham et al. 1995; Sigthorsson et al. 2002). However, this degree of damage does not seem to occur in man although the data are scanty.

The adverse effect data on NSAIDs in man are almost all descriptive and are of three types regardless of whether the stomach or small bowel is being assessed.

1. There are short-term studies where there is an assessment of damage before and after taking the drugs by healthy volunteers who by and large do not have risk factors that may contribute synergistically to the damage (apart from Helicobacter pylori). Interestingly, while the prevalence and severity of the damage in the small bowel is similar with all conventional NSAIDs and not seen with COX-2 selective agents to the same extent (Maiden et al. 2005), the severity of the gastroduodenal damage relates best to the acidity 
$\left(\mathrm{p} K_{\mathrm{a}}\right.$ ) of the drug and the drug formulation suggesting that the topical effect is important in this damage (Scarpignato et al. 1999; Bjarnason et al. 2007).

2. The long-term studies in patients (usually with rheumatoid arthritis or osteoarthrosis) assess the damage after 3 or more months of ingestion. The small bowel data in these studies conform to what is seen in the short-term (Tibble et al. 1999), but there is no clear hierarchy in the order of the gastroduodenal damage caused by these drugs with prevalence of ulcers (almost always defined endoscopically on their size, defined as mucosal break of 3 or $5 \mathrm{~mm}$ or greater and with a depth) variably reported between 15 and $35 \%$ (Fenn 1994). Data analyses show that there are no specific risk factors to the small bowel damage, but Helicobacter pylori and advancing age may increase the prevalence of the gastroduodenal ulcers (Moore et al. 2009).

3. The serious outcome studies (mostly case-control, cohort or epidemiological studies) look at the prevalence of gastroduodenal or lower intestinal bleeds, perforations, obstructions and death in patients with rheumatoid arthritis or osteoarthrosis. In practice, these are bleeding complication studies and most have a whole host of deficiencies of design or conduct that limit specific conclusions being obtained. The more controlled (non-epidemiologic) studies namely the megatrials (MUCOSA, VIGOR, CLASS, MEDAL, SUCCESS, TARGET) demonstrated reduced (about $50 \%$ ) upper gastrointestinal bleeding with the COX-2 selective agents or co-administration of misoprostol with NSAIDs (Silverstein et al. 1995, 2000; Bombardier et al. 2000; Schnitzer et al. 2004; Arora et al. 2010), while the CONDOR trial (Chan et al. 2010) showed a $75 \%$ reduction of more distal intestinal bleeding associated with the use of celecoxib compared with the combination of diclofenac and omeprazole. However, these megatrials do not tell us if there is a significant difference between the various non-selective NSAIDs. Nevertheless, studies from the 1980s had already indicated that upper gastrointestinal bleeding was increased in patients on NSAIDs, that there were specific risk factors associated with the bleeds, such as previous history of a gastric ulcer or ulcer bleed, presence of Helicobacter pylori, advancing age, concomitant aspirin ingestion, low platelet counts, anticoagulation, co-morbidities and the particular (and number of) NSAID being taken (Moore et al. 2009). Collectively, it was shown that ketorolac, piroxicam and indomethacin usually headed the toxicity rankings with ibuprofen and nabumetone being perceived as safer alternatives (Langman 1989; Henry et al. 1993, 1996; Kaufman et al. 1993; MacDonald et al. 1997). A recent study attempts to expand on this (Massó González et al. 2010). The authors conducted a systematic review of observational studies (case-control or cohort studies) on NSAIDs + COX-2 selective agents and gastrointestinal bleeding/perforation in order to assess the relative risk of upper gastrointestinal bleeding and to correlate this risk to whole blood COX-1 and COX-2 inhibition in vitro. The initial screen identified 401 publications that were reduced to nine studies for the meta analyses ( 5 used computerised records and 4 were field-based with patient interviews) with varying exclusion criteria. The results showed and simply confirmed previous findings that the relative risks of gastrointestinal complications due to NSAIDs were dose-related, related to plasma half life of the NSAID, and increased with slow-release formulations of NSAIDs. Again ketorolac, piroxicam and indomethacin headed the toxicity list, while diclofenac and ibuprofen appeared to be safer alternatives with rofecoxib and celecoxib being the safest, but still associated with an increased relative risk of bleeding by twofold. The correlation between relative risk of bleeding/perforation with inhibition of whole blood COX-1 and was $r^{2}=0.34$, $P=0.058$ and with in vitro $\mathrm{COX}-2$ inhibition $r^{2}=0.06, P=0.46$. The authors then discuss some of the theoretical explanations for these findings and add a few speculations themselves all of which are plausible but unproven.

However, the limitations of the study in establishing a cause effect are such as to render the data as a matter of curiosity. What is perhaps most surprising is that it is published in the prestigious journal Arthritis and Rheumatism, which has the highest impact of the clinical rheumatologic journals and yet the amount of new information is so scanty. By virtue of the study design, it is impossible to ascertain a cause-effect relationship, the shortcomings (which are very substantial) of the in vitro and in vivo selectivity for COX-1 and 2 assessments of NSAIDs are not mentioned (Jacob et al. 1998) and there is no comprehensive discussion on why ulcers bleed despite the fact that bleeding is the main outcome measure in their material. The most obvious cause for ulcers (whether they are Helicobacter pylori or NSAID driven) to bleed is impaired vascular homeostasis, which encompasses a whole variety of biochemical events, some of which are affected by NSAIDs. It is, however, less clear how advancing age, co-morbidities, slow-release NSAID formulations (which minimise the topical effect on the stomach), longer acting NSAIDs (unless compliance is a problem), etc. contribute to bleeding as opposed to the development and healing of erosions and ulcers. Furthermore, a comparison with the annual ulcer bleed rate in 
patients that are not on NSAIDs would seem to be relevant and indeed some explanation is required to the fact that the vast majority of NSAID-induced not bleed (the prevalence of bleeding from the two types of ulcers appears to be remarkably similar (Ladwa et al. 2006). There are other confounding factors which epidemiologists are afraid or not able to address. For instance, there is little evidence that the upper gastrointestinal bleeding in patients on NSAIDs is, in fact, from gastroduodenal ulcers, the idea being that the ulcer has depth eroding the muscularis mucosa and hence may erode arteries. Indeed, the serious outcome megatrials show that a significant number of the bleeds are associated with erosions [despite the fact that the definition of ulcer was often set very low (mucosal break of $3 \mathrm{~mm}$ or more)]. Clinically significant gastric bleeds from erosions (outside the ITU setting or in patients with severe clotting or platelet impairment) is very rare, indeed. However, data from the very few trials available that prospectively address patients at very high risk of gastrointestinal bleeding show that a combination of a COX-2 selective agent (celecoxib) and omeprazole (a proton pump inhibitor) prevented re-bleeds completely in these patients (Chan et al. 2007).

Epidemiologists (Chan et al. 2007) would have prescribed no drugs, paracetamol (lacks efficacy in arthritic conditions) or NSAIDs at sub-therapeutic levels which may sound eminently sensible but for the fact that their patients are imaginary while many patients are in dire need of antiinflammatory analgesics. Pragmatic clinical trials show that the safest option for patients at risk for gastrointestinal bleeding due to NSAIDs is to prescribe the combination celecoxib and omeprazole which effectively prevents serious upper gastrointestinal bleeds (Chan et al. 2007). In addition, a COX-2 selective agent (celecoxib) is associated with fewer small intestinal complications as compared with the use of NSAIDs administered with a proton pump inhibitor (Chan et al. 2010). It seems to us that we need fewer epidemiological studies and more information driven research on the topic.

\section{References}

Arora G, Singh G, Vadhavkar S, Shah SB, Mannalithara A, Mithal A, Triadafilopoulos G (2010) Incidence and risk of intestinal and extra-intestinal complications in Medicaid patients with inflammatory bowel disease: a 5-year population-based study. Dig Dis Sci 55:1689-1695

Bjarnason I, Hayllar J, Macpherson AJ, Russell AS (1993) Side effects of nonsteroidal anti-inflammatory drugs on the small and large intestine. Gastroenterology 104:1832-1847

Bjarnason I, Scarpignato C, Takeuchi J, Rainsford KD (2007) Determinants of the short-term gastric damage caused by NSAIDs in man. Aliment Pharmacol Ther 26:95-106
Bombardier C, Laine L, Reicin A, Shapiro D, Burgos-Vargas R, Davis B, Day R, Ferraz MB, Hawkey CJ, Hochberg MC, Kvien TK, Schnitzer TJ (2000) Comparison of upper gastrointestinal toxicity of rofecoxib and naproxen in patients with rheumatoid arthritis VIGOR Study Group. N Engl J Med 343:1520-1528

Chan FK, Wong VW, Suen BY, Wu JC, Ching JY, Hung LC, Hui AJ, Leung VK, Lee VW, Lai LH, Wong GL, Chow DK, To KF, Leung WK, Chiu PW, Lee YT, Lau JY, Chan HL, Ng EK, Sung JJ (2007) Combination of a cyclo-oxygenase-2 inhibitor and a proton-pump inhibitor for prevention of recurrent ulcer bleeding in patients at very high risk: a double-blind, randomised trial. Lancet 369:1621-1626

Chan FK, Lanas A, Scheiman J, Berger MF, Nguyen H, Goldstein JL (2010) Celecoxib versus omeprazole and diclofenac in patients with osteoarthritis and rheumatoid arthritis (CONDOR): a randomised trial. Lancet 376:173-179

Fenn GC (1994) Controversies in NSAID-induced gastroduodenal damage-do they matter? Aliment Pharmacol Ther 8:15-26

Hayllar J, Macpherson A, Bjarnason I (1992) Gastroprotection and nonsteroidal anti-inflammatory drugs. Drug Safe 7:86-105

Henry D, Dobson A, Turner C (1993) Variability in the risk of major gastrointestinal complications from nonsteroidal anti-inflammatory drugs. Gastroenterology 105:1078-1088

Henry D, Lim LL-Y, Rodrigues LAG, Gutthann PS, Carson JL, Griffin M, Savage R, Logan R, Moride Y, Hawkey C, Hill S, Fries JT (1996) Variability in risk of gastrointestinal complications with individual non-steroidal anti-inflammatory drugs: results of a collaborative meta-analysis. Br Med J 312:1563-1566

Jacob M, Simpson R, Bjarnason I (1998) Nonsteroidal anti-inflammatory drugs, cyclooxygenase selectivity and gastrointestinal toxicity. Ital J Gastroenterol Hepatol 30:12-18

Kaufman DW, Kelly JP, Sheehan JE, Laszlo A, Wiholm BE, Alfredsson L, Koft RS, Shapiro S (1993) Nonsteroidal antiinflammatory drug use in relation to major gastrointestinal bleeding. Clin Pharmacol Ther 53:485-494

Ladwa M, Takeuchi K, Bjarnason I (2006) NSAIDs request parity with Helicobacter pylori. Scand J Gastroenterol 41:373-375

Langman MJS (1989) Epidemiological evidence on the association between peptic ulceration and antiinflammatory drugs. Gastroenterology 96:640-646

MacDonald TM, Morant SV, Robinson GC, Shield MJ, McGilchrist MM, Murray FE, McDevitt DG (1997) Association of upper gastrointestinal toxicity of non-steroidal anti-inflammatory drugs with continued exposure: cohort study. Br Med J 315:1333-1337

Maiden L, Thjodleifsson B, Theodors A, Gonzalez J, Bjarnason I (2005) A quantitative analysis of NSAID-induced small bowel pathology by capsule enteroscopy. Gastroenterology 128:1172-1178

Massó González EL, Patrignani P, Tacconelli S, García Rodríguez LA (2010) Variability among nonsteroidal antiinflammatory drugs in risk of upper gastrointestinal bleeding. Arthritis Rheum 62:1592-1601

Moore A, Bjarnason I, Cryer B, Garcia-Rodriguez L, Goldkind L, Lanas A, Simon L (2009) Evidence for endoscopic ulcers as meaningful surrogate endpoint for clinically significant upper gastrointestinal harm. Clin Gastroenterol Hepatol. 7:1156-1163

Morham SG, Langenbach R, Loftin CD, Tiano HF, Vouloumanos N, Jennette JC, Mahler JF, Kluckman KD, Ledford A, Lee CA, Smithies O (1995) Prostaglandin synthase 2 gene disruption causes severe renal pathology in the mouse. Cell 83:473-482

Scarpignato C, Bjarnason I, Bretagne J-F, de Pouvourville G, Garcia Rodriguez LA, Goldstein JL, Muller P, Simon B (1999) Towards a GI safer antiinflammatory therapy. Gastroenterol Int 12:180-215

Schnitzer TJ, Burmester GR, Mysler E, Hochberg MC, Doherty M, Ehrsam E, Gitton X, Krammer G, Mellein B, Matchaba P, Gimona A, Hawkey CJ (2004) Comparison of lumiracoxib with naproxen and ibuprofen in the Therapeutic Arthritis Research 
and Gastrointestinal Event Trial (TARGET), reduction in ulcer complications: randomised controlled trial. Lancet 364:665-674 Sigthorsson G, Simpson RJ, Walley M, Anthony A, Foster R, HotzBehoftsitz C, Palizban A, Pombo J, Watts J, Morham SG, Bjarnason I (2002) COX-1 and 2, intestinal integrity and pathogenesis of NSAID-enteropathy in mice. Gastroenterology 122:1913-1923

Silverstein FE, Graham GY, Senior JR, Davies HW, Struthers BJ, Bittman RM, Geis SG (1995) Misoprostol reduces serious gastrointestinal complications in patients with rheumatoid arthritis receiving nonsteroidal anti-inflammatory drugs. Ann Int Med 123:241-249

Silverstein FE, Faich G, Goldstein JL, Simon LS, Pincus T, Whelton A, Makuch R, Eisen G, Agrawal NM, Stenson WF, Bur AM, Zhao WW, Kent JD, Lefkowith JB, Verburg KM, Geis GS
(2000) Gastrointestinal toxicity with celecoxib vs nonsteroidal anti-inflammatory drugs for osteoarthritis and rheumatoid arthritis: the CLASS study: a randomised controlled trial. Celecoxib Long-term Arthritis Study. JAMA 284:1247-1255

Somasundaram S, Hayllar J, Rafi S, Wrigglesworth J, Macpherson A, Bjarnason I (1995) The biochemical basis of NSAID-induced damage to the gastrointestinal tract: a review and a hypothesis. Scand J Gastroenterol 30:289-299

Tibble J, Sigthorsson G, Foster R, Scott D, Roseth A, Bjarnason I (1999) Faecal calprotectin: a simple method for the diagnosis of NSAID-induced enteropathy. Gut 45:362-366

Wallace JL, McKnight W, Reuter BK, Vergnolle N (2000) NSAIDinduced gastric damage in rats: requirement for inhibition of both cyclooxygenase 1 and 2. Gastroenterology 119:706-714 